\title{
A dimensão geopolitica da pandemia de coronavírus
}

I ${ }^{1}$ Paulo Henrique de Almeida Rodrigues, ${ }^{2}$ Lusiana Chagas Gerzson I

\author{
${ }^{1}$ Instituto de Medicina Social, Universidade do Estado do Rio de Janeiro. Rio de Janeiro-RJ, Brasil (pharodrigues@gmail.com). \\ ORCID: 0000-0002-3159-6711 \\ 2 Secretaria Municipal de Saúde. Rio de Janeiro-RJ, Brasil (lusianachagas@yahoo.com.br). ORCID: 0000-0001-8411-4213 \\ Recebido em: 21/04/2020 \\ Aprovado em: 25/04/2020 \\ Revisado em: 27/04/2020
}

DOI: http://dx.doi.org/10.1590/S0103-73312020300209

Desde o final do ano passado, começou a se desenvolver a atual pandemia de Covid-19. Segundo artigo publicado na prestigiada revista Nature, por Kristian Andersen e outros (2020), o coronavírus é o nome de uma família de vírus, com sete espécies que atacam os seres humanos. Três espécies provocam doenças severas: Mers-Cov, que causa a síndrome respiratória do Oriente Médio; a SARS-Cov, que causa a síndrome respiratória aguda grave; e o SARS-Cov 2, que causa a Covid-19 e provocou a atual pandemia (OPAS, 2020).

Os primeiros casos ocorreram na China e logo alimentaram a já tensa disputa geopolítica entre este país e os Estados Unidos (EUA), com acusaçóes mútuas sobre a possibilidade de o vírus ser uma arma biológica. Tal disputa contribuiu para a associação da doença à China e à cidade de Wuhan - Donald Trump passou a falar em "vírus da China” e seu secretário de Estado, Mike Pompeo, em "vírus de Wuhan” (POLITICO, 2020). Diante da intensa polêmica, a própria revista Nature (2020) se viu obrigada a fazer um editorial em que se desculpou por ter contribuído erradamente para essa associação.

A disputa sobre a origem continua acirrada; recentemente, reportagem do The Washington Times relatou declaração de Trump de que os órgãos de inteligência dos EUA estavam investigando se o vírus é "man-made" e teria escapado do Instituto 
de Virologia de Wuhan, numa clara tentativa de culpar as autoridades chinesas (GERTZ, 2020). Antes disso, a primeira hipótese era de que a transmissão teria se iniciado em mercado de frutos do mar existente em Wuhan, que chegou a ser fechado. Entretanto, a comunidade científica da China, com o objetivo de agilizar o tratamento e salvar vidas, passou a investigar minuciosamente os casos e reunir informações sobre os mesmos. O ponto-chave para as pesquisas era descobrir o paciente zero, a primeira pessoa infectada; entretanto, a resposta para esse enigma ainda não foi encontrada (ROMANOFF, 2020).

No decorrer das investigaçôes, a probabilidade de que a doença pudesse ter se originado em outro local aumentou. Com a análise detalhada de amostras das distintas variedades do vírus, coletadas em 12 países em quatro continentes, os chineses identificaram que o surto poderia ter começado muito antes. Eles levaram em consideração a realização dos Jogos Mundiais Militares de Wuhan, em novembro de 2019. É possível que a transmissão tenha ocorrido durante o evento, no qual estiveram 300 atletas dos EUA. O principal especialista respiratório da China, Zhang Nanshan declarou, em 27/01/2020, que embora a Covid-19 tenha sido descoberta na China pela primeira vez, isso não significava que tivesse se originado na China (ROMANOFF, 2020). Existem diversos tipos de coronavírus, e a lógica básica é que a localização geográfica com maior diversidade de linhagens de vírus é o local onde a doença se origina. São os Estados Unidos o único país onde foram encontradas as cinco linhagens conhecidas do vírus, enquanto em Wuhan e na maior parte da China só há uma linhagem (ROMANOFF, 2020).

Outros fatos alimentam as suspeitas de uma hipotética origem estadunidense, como o fechamento, em agosto de 2019, pelo Centro de Controle de Doenças dos EUA (CDC,) do laboratório de pesquisa biológica do exército estadunidense, Fort Detrick, em Maryland, por falta de condiçóes de segurança adequadas (NEW YORK TIMES, 2019), embora o artigo mencionado da revista Nature (mar. 2020) afirme claramente que o vírus tem origem natural. A partir dessas suspeitas, o portavoz do Ministério da Relaçóes Exteriores da China, Zhao Lijian, disse que o surto de coronavírus em Wuhan poderia ser fruto de uma possível guerra biológica movida pelos EUA contra a China (O GLOBO, 2020).

As acusaçóes trocadas entre EUA e China em torno da doença ocorrem no bojo de uma disputa geopolítica muito mais ampla. Os dois países estấo mergulhados, desde janeiro de 2018, numa guerra comercial (PODER360, 2020); há disputas em 
torno de supostas violaçôes dos direitos humanos pela China em Xinjiang, Tibet e Hong Kong, levantados pelos EUA. O Congresso estadunidense chegou a aprovar, em outubro de 2019, uma lei de direitos humanos e democracia em Hong Kong - Hong Kong Human Rights and Democracy Act (CONGRESS.GOV). A disputa política e ideológica entre os dois países adquire, por vezes, caráter dramático e ofensivo. No final de janeiro deste ano, por exemplo, Mike Pompeo, Secretário de Estado americano, chamou o Partido Comunista da China de "a ameaça central de nossos tempos" (ORTEGA; MARÍN, 2020).

O conflito tem suas raízes no rápido crescimento econômico chinês, desde as reformas econômicas dos anos 1980, tendo a economia chinesa ultrapassado a dos EUA em 2014 pelo critério da paridade do poder de compra da moeda, segundo o Programa de Comparação Internacional do Banco Mundial (O GLOBO, 2014). Enquanto a China vem crescendo com base no aumento da produção de bens e da construção de uma moderníssima infraestrutura, os EUA vêm passando por um processo acelerado de desindustrializaçáo, acompanhado de uma crescente especulação no seu mercado financeiro, que já causou a crise mundial de 2008 e está por trás da atual crise das Bolsas (BLYTH, 2017; AMADEO, 2020).

Como consequência da desindustrialização, os EUA ficaram vulneráveis aos efeitos da pandemia, dependentes de importaçóes de produtos chineses. Surpreendentemente, como forma de driblar a carência de equipamentos, resolveram desviar produtos pretendidos por outros países e virando alvo de críticas de pirataria por países aliados, como Alemanha, França, Itália, além do Brasil (BBC, 2020a). Em contraste, a China vem fazendo doaçôes de equipamentos e enviando equipes médicas para diversos países (XINHUANET, 2020; TREMANN, 2020). Como se não bastasse o desgaste que a imagem dos EUA vem sofrendo, tanto com a enorme dificuldade do governo para enfrentar a grave situação sanitária em seu país, quanto com as acusaçôes de pirataria, Trump decidiu interromper o financiamento das contribuiçôes do país à Organização Mundial da Saúde (OMS), acusando-a de lidar de forma inadequada com a pandemia e dar atenção exagerada à China (SMITH, 2020).

A evolução da pandemia tem sido muito desfavorável para os EUA, em relação à China. Em 19 de abril, o número de casos nos EUA atingiu 764.053, e o de mortos pela doença chegou a 40.432 , enquanto os números chineses eram muito inferiores, ou 82.735 casos e 4.632 mortes (WORLDOMETER, 19 abr. 2020). As estratégias de controle iniciais foram muito diferentes. A China, onde a epidemia se desenvolveu 
inicialmente, adotou uma tática inédita de supressão da epidemia, com interrupção das atividades econômicas e radical isolamento social com quarentena domiciliar para toda a população, que foi muito bem-sucedida. Já os EUA demoraram para adotar o isolamento social, mantendo as atividades econômicas e sociais até um agravamento maior da situação.

Além da interrupção da atividade econômica e a determinação de quarentena para a população, a China lançou mão de diversas medidas radicais de controle, entre as quais se destacaram: a construçáo, em grande velocidade, de hospitais para isolar os pacientes; treinamento e mobilização de profissionais de saúde, militares e voluntários para o controle da doença; desenvolvimento e produçáo em massa de testes rápidos; equipamentos de proteção individual; ventiladores mecânicos para os hospitais; e termômetros eletrônicos (ESCOBAR, 2020). As medidas envolveram, ainda, o desenvolvimento de sofisticados sistemas de informação em computadores e celulares para agilizar a notificação de casos, controle de deslocamentos de pessoas, além de desinfecção do dinheiro, calçadas e entradas de prédios públicos e residenciais. O governo chinês declarou uma "guerra popular", com grande adesão da população, liderada por seus comitês de bairro, seja no cumprimento da quarentena, seja em tarefas coletivas de controle, abastecimento, educação e desinfecção de ambientes (ZHONG; MOZUR, 202020; AKFIRAT, 2020). Uma boa medida do sucesso da experiência chinesa foi o de ter limitado o surto basicamente à província de Hubei, onde fica Wuhan, reduzindo rapidamente o número de novos casos e mortes.

Nos EUA, a doença se espalhou em diversos pontos do território; além disso, a ausência de um sistema público de saúde vem tornando ainda mais difícil a organização de açôes efetivas de controle e tratamento (BBC, 2020b). O próprio presidente Donald Trump tem ajudado a confundir a populaçáo, ao pregar o uso da cloroquina como medicamento capaz de tratar a Covid-19, enquanto estudos recentes mostram não haver evidência suficiente que dê suporte a tal defesa, inclusive em recentíssimo estudo publicado no prestigioso The Lancet (TACCONE et al., 2020). A defesa de Trump a respeito da administração do medicamento é, ainda, um exemplo concreto de conflito de interesse, uma vez que é sócio da Sanofi, empresa que detém a patente da droga (PANORAMA FARMACÊUTICO, 2020).

No Brasil, o Governo Federal também resolveu se alinhar aos EUA na disputa geopolítica em torno da pandemia. Os recentes ataques à China por um dos filhos do presidente e pelo ministro da Educação são demonstrativos desse alinhamento, além 
da defesa do medicamento cloroquina como tratamento eficaz para a Covid-19, em uníssono com Donald Trump dos EUA (ORTEGA; MARÍN, 2020). O controle da doença no país vem sendo dificultado, ainda, pelas divergências entre o Governo Federal e os governos estaduais e municipais. Governadores e prefeitos vêm tomando medidas cada vez mais drásticas de redução da circulação de pessoas, para tentar conter, além da epidemia, o iminente colapso da capacidade de o SUS atender os pacientes. Enquanto isso, o presidente Jair Bolsonaro defende o fim do isolamento social e o retorno à "normalidade"; substituiu o ministro da Saúde em um período crítico de aumento do número de casos e mortes e, ultimamente, passou a propor o fechamento do Congresso Nacional e do Supremo Tribunal Federal, numa clara manobra golpista contra seus opositores (VENCESLAU; LINDNER, 2020).

Os efeitos da pandemia sob o cenário mundial vêm desencadeando mudanças de consequências ainda imprevisíveis. Uma delas é o agravamento da crise econômica que se manifestou no início do ano com a recente e acentuada queda das Bolsas de Valores; há fortes indícios de que a economia mundial esteja entrando numa das mais sérias crises da história (FITCH RATINGS, 2020). Donald Trump e grandes grupos de mídia vêm se apressando a colocar a culpa na doença, embora diversos analistas viessem chamando a atenção para um intenso e irracional processo de especulação sem qualquer base na economia real e que iria estourar mais cedo ou mais tarde (ROONEY, 2020). Aqui no Brasil, além da queda das Bolsas, o país está assistindo a uma enorme perda do valor do real diante do dólar (GAZETA DO POVO, 2020), queda da atividade econômica e desemprego recordes, além de uma das maiores fugas de investimentos de toda sua história (HOLTZ; PIOVESANA, 2020; SEU DINHEIRO, 2020).

Ainda é impossível prever todas as consequências sanitárias, sociais e econômicas da pandemia, mas pode-se adiantar, entretanto, que ela está acelerando e agravando a disputa entre a China e os EUA, assim como a perda de importância e influência dos países que compóem o G7 - EUA, Japão, Alemanha, França, Inglaterra, Itália e Canadá. O neoliberalismo como doutrina econômica e ideologia dominante tende a ruir diante de suas consequências nocivas sobre as economias e as sociedades. Décadas de neoliberalismo deixaram os sistemas de proteção social e de saúde enfraquecidos em todo o mundo, inclusive nos países até agora mais ricos. $\mathrm{O}$ enfrentamento da pandemia e da crise econômica vem se mostrando impossível sem a intervenção estatal, o que pôe por terra as ideias e políticas neoliberais. Ao final 
da pandemia, emergirá um mundo completamente distinto, com um protagonismo muito maior do Oriente, além de contar com Estados mais atuantes na economia e nas políticas sociais.

\section{Referências}

AKFIRAT, A. The Secret of China's Success: Neighborhood Committees. Defend Democracy Press, 12 abr. 2020. Disponível em: <http://www.defenddemocracy.press/the-secret-of-chinassuccess-neighborhood-committees/>. Acesso em: 15 abr. 2020.

AMADEO, K. How Does the 2020 Stock Market Crash Compare with Others? The Balance, 17 mar. 2020. Disponível em: <https://www.thebalance.com/fundamentals-of-the-2020market-crash-4799950>. Acesso em: 19 abr. 2020.

ANDERSEN, K. G. W. et al. The proximal origin of SARS-CoV-2. Nat Med., v. 26, p. 450-452, 2020). Disponível em: <https://doi.org/10.1038/s41591-020-0820-9>. Acesso em: 20 mar. 2020.

BBC. Coronavírus: EUA são acusados de "pirataria" e "desvio" de equipamentos que iriam para Alemanha, França e Brasil. BBC, 04/04/20. Disponível em: <https://www.bbc.com/ portuguese/internacional-52166245>. Acesso em: 19 abr. 2020a.

. Coronavírus: 4 fatores que explicam o impacto da covid-19 nos EUA, país com maior número de infectados e mortos. BBC, 14/04/20. Disponível em: <https://www.bbc.com/ portuguese/internacional-52280762>. Acesso em: 19 abr. 2020b.

BLYTH, M. Austeridade: A História de uma Ideia Perigosa. São Paulo: Autonomia Literária, 2017, $400 \mathrm{p}$.

CONGRESS.gov. H.R.3289. Hong Kong Human Rights and Democracy Act of 2019. Disponível em: <https://www.congress.gov/bill/116th-congress/house-bill/3289>. Acesso em: 20 mar. 2020.

ESCOBAR, P. China's virus response has been 'breathtaking'. Asia Times, 30 jan. 2020. Disponível em: <>https://asiatimes.com/2020/01/is-china-at-its-most-vulnerable-now/. Acesso em: 05 fev. 2020.

FITCH RATINGS. Deep Global Recession in 2020 as Coronavirus Crisis Escalates. Fitch Ratings, 02 abr. 2020. Disponível em: <https://www.fitchratings.com/research/sovereigns/deepglobal-recession-in-2020-as-coronavirus-crisis-escalates-02-04-2020>. Acesso em: 20 abr. 2020.

GAZETA DO POVO. Real foi a terceira moeda que mais se desvalorizou frente ao dólar em 2020. Gazeta do Povo, 20 abr. 2020. Disponível em: <https://www.gazetadopovo.com.br/ economia/breves/dolar-desvalorizacao-real/>. Acesso em: 20 abr. 2020.

GERTZ, B. Trump confirms U.S. investigating reports virus came from Chinese lab. The Washington Times, 17 abr. 2020. Disponível em: <https://www.washingtontimes.com/news/2020/ apr/17/trump-confirms-us-investigating-reports-virus-came/>. Acesso em: 19 abr. 2020. 
GRADY, D. Deadly Germ Research Is Shut Down at Army Lab Over Safety. The New York Times, 05 ago. 2019. Disponível em: <https://www.nytimes.com/2019/08/05/health/germsfort-detrick-biohazard.html>. Acesso em: 20 mar. 2020.

HOLTZ, F.; PIOVESANA, M. Em 43 pregóes, fuga de capital estrangeiro da Bolsa em 2020 já supera o ano de 2019. Estado de Sáo Paulo, 06 mar. 2020. Disponível em: <https://economia. estadao.com.br/noticias/geral,em-43-pregoes-saida-de-estrangeiros-da-bolsa-em-2020-jasupera-o-ano-de-2019,70003222857>. Acesso em: 20 abr. 2020.

NATURE. Stop the coronavirus stigma now (Editorial). Nature, 07 abr. 2020. Disponível em: <https://www.nature.com/articles/d41586-020-01009-0>. Acesso em: 10 abr. 2020.

O GLOBO. Porta-voz da China sugere que militares dos EUA levaram coronavírus para o país. O Globo, 12 mar. 2020. Disponível em: <https://oglobo.globo.com/mundo/porta-vozda-china-sugere-que-militares-dos-eua-levaram-coronavirus-para-pais-24300774>. Acesso em: 20 mar. 2020.

OPAS Brasil. Folha informativa - COVID-19 (doença causada pelo novo coronavírus). Disponível em: <https://www.paho.org/bra/index.php?option=com_content\&view=article\&id =6101:covid19\&Itemid=875>. Acesso em: 19 abr. 2020 .

ORTEGA, A.; MARÍN, P. O coronavírus e a propaganda anti-China. Revista Opera. 22 mar. 2020. Disponível em: <https://revistaopera.com.br/2020/03/22/o-coronavirus-e-a-propagandaanti-china/>. Acesso em: 12 abr. 2020.

PANORAMA FARMACÊUTICO. Trump é sócio de empresa que produz cloroquina. Panorama Farmacêutico, 08 abr. 2020. Disponível em: <https://panoramafarmaceutico.com. br/2020/04/08/trump-e-socio-de-empresa-que-produz-cloroquina-defendida-por-ele-comoeficaz-contra-a-covid-19-diz-nyt/>. Acesso em: 20 abr. 2020.

PODER 360. Os capítulos e efeitos da guerra comercial entre EUA e China. Poder 360, 11 jan. 2020. Disponível em: <https://www.poder360.com.br/economia/os-capitulos-e-efeitos-daguerra-comercial-entre-eua-e-china/>. Acesso em: 25 mar. 2020.

POLITICO. Pompeo, G-7 foreign ministers spar over 'Wuhan virus'. Politico, 25 mar. 2020. Disponível em: <https://www.politico.com/news/2020/03/25/mike-pompeo-g7coronavirus-149425>. Acesso em: 30 mar. 2020.

ROMANOFF, L. COVID-19: Further Evidence that the Virus Originated in the US. Global Research, 11 mar. 2020. Disponível em: <https:/www.globalresearch.ca/covid-19-furtherevidence-virus-originated-us/5706078>. Acesso em: 20 mar. 2020.

ROONEY, S. Corona Pandemic: The Perfect Scapegoat for the Financial and 'Everything Bubble' Market Crash: The Great Depression 2.0. Global Research, 06 abr. 2020. Disponível em: <https:/www.globalresearch.ca/corona-pandemic-scapegoat-financial-bubble-marketcrash-great-depression/5708772>. Acesso em: 20 abr. 2020. 
SEU DINHEIRO. Saída de dólar supera entrada em US\$10,791 bilhóes no ano até dia 27 de março, diz BC. Seu dinheiro, 01 abr. 2020. Disponível em: <https://www.seudinheiro. com/2020/economia/saida-de-dolar-supera-entrada-em-us-10791-bilhoes-no-ano-ate-dia-27de-marco-diz-bc/>. Acesso em: 20 abr. 2020.

SMITH, D. Trump halts World Health Organization funding over coronavirus "failure". The Guardian, 15 abr. 2020. Disponível em: <https://www.theguardian.com/world/2020/apr/14/ coronavirus-trump-halts-funding-to-world-health-organization>. Acesso em: 18 abr. 2020.

TACCONE, F. S.; GORHAM, J.; VINCENT, J. Hydroxychloroquine in the management of critically ill patients with COVID-19: the need for an evidence base. The Lancet, 15 abr. 2020. Disponível em: <https://doi.org/10.1016/S2213-2600(20)30172-7>. Acesso em: 19 abr. 2020.

TREMANN, C. As Africa prepares to fight Covid-19, China steps up. The Interpreter, 15 abr. 2020. Disponível em: <https://www.lowyinstitute.org/the-interpreter/africa-prepares-fightcovid-19-china-steps-up>. Acesso em: 18 abr. 2020.

WORLDOMETER. Covid-19 Coronavirus Pandemic. Worldometer, 19 abr. 2020. Disponível em: <>https://www.worldometers.info/coronavirus/. Acesso em: 19 abr. 2020.

VENCESLAU, P.; LINDNER, J. Discurso de Bolsonaro “incentiva desobediência” e é "escalada antidemocrática”, dizem políticos. O Estado de São Paulo, 19 abr. 2020. Disponível em: <https:// politica.estadao.com.br/noticias/geral,discurso-de-bolsonaro-incentiva-desobediencia-e-eescalada-antidemocratica-dizem-politicos,70003276430>. Acesso em: 19 abr. 2020.

XIAOJUN, D.; PRASHAD, V.; ZHU, W. How China broke the chain of infection. Brasil de Fato, 15 abr. 2020. Disponível em: <https://www.brasildefato.com.br/2020/04/15/how-chinabroke-the-chain-of-infection>. Acesso em: 18 abr. 2020.

XINHUANET. Commentary: China's COVID-19 aid is humanitarian, not geopolitical. Xinhuanet, 04 abr. 2020, Disponível em: <http://www.xinhuanet.com/english/202004/04/c_138946777.htm>. Acesso em: 18 abr. 2020.

ZHONG, R.; MOZUR, P. Para domar o coronavírus, China vigia mais de 760 milhóes de pessoas. O Globo, 18 fev. 2020. Disponível em: <https://oglobo.globo.com/sociedade/ coronavirus/para-domar-coronavirus-china-vigia-mais-de-760-milhoes-de-pessoas-24253569>. Acesso em: 29 fev. 2020. 